\title{
Developing local entrepreneurial ecosystems through integrated learning initiatives: the Lancaster case
}

\author{
Rhiannon Pugh • Danny Soetanto • Sarah L. Jack • \\ Eleanor Hamilton
}

Accepted: 18 June 2019 /Published online: 11 November 2019

(C) Springer Science+Business Media, LLC, part of Springer Nature 2019

\begin{abstract}
This paper considers a concept gaining popularity: entrepreneurial ecosystems. It finds a significant lacuna in the concept as it stands as it does not sufficiently consider learning within regional ecosystems. Considering the established centrality of learning for entrepreneurial activity and regional development, it is surprising that the entrepreneurial ecosystem literature does not yet incorporate how learning occurs in time and space within regional ecosystems. This paper presents research conducted in the North West of England over (20) years examining programmes to support entrepreneurial and regional development. It argues that learning, and the pro-active support thereof, is crucial within
\end{abstract}

R. Pugh

School of Humanities, Education and Social Sciences, Örebro

University, SE-701 82 Örebro, Sweden

e-mail: rhiannon.pugh@oru.se

D. Soetanto $\cdot$ S. L. Jack $(\bowtie) \cdot$ E. Hamilton

Department of Entrepreneurship and Strategy, Lancaster

University Management School, Lancaster University, Bailrigg,

Lancaster LA1 4YX, UK

e-mail: sarah.jack@hhs.se

D. Soetanto

e-mail: d.soetanto@lancaster.ac.uk

E. Hamilton

e-mail: e.hamilton@lancaster.ac.uk

\section{S. L. Jack}

House of Innovation, Jacob and Marcus Wallenberg Centre for Innovative and Sustainable Business Development, Stockholm School of Economics, Box 650, SE-113 83 Stockholm, Sweden an entrepreneurial ecosystem and should be fully considered within theoretical frameworks and policy blueprints designed to support and encourage entrepreneurship within regions. As a tangible suggestion of how to theoretically incorporate learning into entrepreneurship ecosystem development efforts, we present an integrated learning model developed by entrepreneurship scholars through collaborations with practitioners.

Keywords Entrepreneurial ecosystem · Learning region $\cdot$ Entrepreneurial learning $\cdot$ Entrepreneurial universities

JEL classification $\mathrm{O} 1 \cdot \mathrm{R} 11 \cdot \mathrm{L} 26$

\section{Introduction}

Recently, the fields of entrepreneurship, economic geography and urban economics have moved closer to each other as some commonalities in research interests have become recognised (Zahra et al. 2014; Autio et al. 2014). These trends are encapsulated in the emerging concept of the entrepreneurial ecosystem (EE) that explicitly focuses on certain entrepreneurial actors in the urban and regional context, such as 'high-growth startups' (Acs et al. 2017; Spigel 2017; Alvedalen and Boschma 2017). Compared to the previous concept of territorial development that focused mainly on selfemployment and small firms (Fischer and Nijkamp 1988; Camagni 2017; Johansson et al. 2011), EE emphasises the role of entrepreneurs and the broader social 
context that enables entrepreneurial actions (Stam 2015). Studies have explored the factors that are necessary to create and sustain high-growth entrepreneurship within regions (e.g. Spigel 2016; Stam 2015; Pitelis 2012; Audretsch and Belitski 2017). The ecosystem contains, among other factors, cultural, social and material attributes that provide benefits and resources to entrepreneurs (Spigel 2016). The EE concept argues that entrepreneurship flourishes through an integrated coordination of resources and actors which appear to be locally based, requiring face-to-face contact or local mobility (Stam 2014). Furthermore, it is believed that the presence of local universities as a part of the ecosystem can foster entrepreneurship and innovation (Miller and Acs 2017). Indeed, universities, science parks and incubators have been identified by previous work as key nodes or hubs in the EE (Bliemel et al. 2019; Cumming et al. 2019; Liguori et al. 2019; Miller and Acs 2017; Malecki 2018). However, Spigel (2016) highlights that the mere presence of such structures does not ensure they will be productively used. Thus far the research has focussed much more on the hard infrastructure and presence of such institutions rather than the dynamics and interplay between them and the region, back and forth, with little discussion of the softer mechanisms therein. Whilst technology transfer is well researched, less is currently known about the roles of universities within the EE as learning institutions.

Whilst the EE concept has received increasing attention from policy makers and researchers alike, and indeed has become something of a 'buzzword', there is still a paucity in the discourse about the role of local actors in realising regional high-growth potentials. This is in part because the majority of studies of the EE concept have used a static approach focusing only on the importance of conditions for entrepreneurship or predefined social context and relationship among the entrepreneurial actors (Mack and Mayer 2015). In particular, EE has failed to leverage the idea of learning, which allows new ventures to accelerate their growth potential. This study extends the literature on EE by advocating for the role of universities as a catalyst for creating and sustaining high-growth entrepreneurial activities in regions. In this case, universities' roles go beyond traditional support for entrepreneurship, which mainly focus on the creation of entrepreneurial actions such as academic spin-offs or licensing activities towards regional culture change and network building activities. We develop the EE concept in a manner which encourages universities to fulfil their functions in society by engaging in learning and knowledge transfer activities that connect universities with business in their locality and regions (Huggins et al. 2008; Boucher et al. 2003). As a result, it allows entrepreneurial firms to discover and evaluate opportunities and exploit them in order to add as much value as possible (Stam et al. 2012).

To investigate the role of learning within a regional entrepreneurial ecosystem, we present a case study of the North West of England, which encompasses a number of activities and programmes implemented over the past 20 years, all with learning as a central principle. By analysing these programmes - how they were designed, what they did, who they involved and what the outcomes were-we provide some tangible examples as to how learning can be better embedded within regional entrepreneurial ecosystems, and how key players in the system such as higher education institutions can take a key role as the facilitators and 'cheerleaders' of learning activities at the individual entrepreneurial level but also at the wider regional level. This paper concludes by reflecting back onto the entrepreneurial ecosystem concept itself and suggesting that by incorporating learning more holistically, via an integrated learning model, the potential of EE as a guide for regional development, and also as an analytical tool for understanding what is happening 'on the ground' within entrepreneurial and business localities is enhanced.

\section{Background}

The study adds a fresh perspective on the entrepreneurial ecosystem concept by bringing together two different perspectives on learning and entrepreneurship: one is taken from entrepreneurial learning theory and the other from the concept of learning regions found within regional economic geography literatures. We then relate this discussion to some practical or 'real world' efforts to develop the regional ecosystem by a university via programmes for entrepreneurial learning aimed at both entrepreneurs and small businesses and public sector actors. We see a great potential for university designed and delivered programmes to support entrepreneurial and regional learning for better social and economic outcomes for people and places. We also see the EE approach holding great promise for local economic development strategies and aim to enrich it by adding the 
learning dimension theoretically into the concept, but also by giving some tangible examples of how an orientation towards learning at both the regional and entrepreneurial level can enrich our efforts to support economic development.

The reason for bringing together work on individual and regional learning is that the EE concept is lacking a learning perspective to explain how entrepreneurship, innovation, and economic development happen at the regional level. We argue that we cannot understand economic growth and development within the globalised knowledge economy without giving sufficient regards to learning as a mechanism for growth, but also to the institutions, actors and processes involved therein. This is where the entrepreneurial ecosystems concept holds great promise: in its ability to conceptualise the actors and institutions at a local and regional level that drive economic development, the evolution of the system and the interrelations between the various parts.

\subsection{Learning for growth: from individual to regional} learning

Within the field of entrepreneurship, there has been a shift to trying to understand how entrepreneurs learn and what impacts on their learning process (Harrison and Leitch 2005; Dimov 2007; Morris et al. 2012). Involving both the acquisition and application to new situations of new knowledge, learning is seen to be especially important and one way to enhance organisational and individual entrepreneurial performance (Jones et al. 2010). Drawing on work in organisational learning (Lumpkin and Lichtenstein 2005) and the theoretical developments offered by Kolb (1984), Mezirow (1991) and Argyris and Schon (1996), learning within the entrepreneurial context has shown that experiential learning is especially critical for entrepreneurs (Cope 2003; Corbett 2005; Gordon and Jack 2010). Recently, Myers (2018) has proposed the theoretical concept of coactive vicarious learning to illustrate how experiential learning occurs via a two-way street of interactions, against the backdrop of individual, relational and structural context in organisations.

Moving up to the regional level perspective, learning is considered vital to economic growth, alongside innovation, knowledge, networks, entrepreneurs and proximities (Storper 2010). Knowledge and learning processes are seen as being geographically embedded at the regional level, and the regional embeddedness of networks means that interaction within them is subject to regional conventions, as the 'learning region' thesis tells us (Rutten and Boekema 2007, p. 131).

According to Lundvall (1992), knowledge is the most strategic resource, and learning is the most important process in economic development. Geography is key because spatial proximity to knowledge can bestow competitive advantage (Audretsch and Aldridge 2009, p. 201). Emphasis is placed on tacit knowledge, which is seen as particularly location dependent, context specific and embodied in people, and so does not travel easily; it cannot be removed from its social context (Morgan 2004, 2007). The importance of tacit knowledge and know-how in the literature is part of a wider argument about the role of intangible and invisible factors in economic development (Morgan 2007, p. 105). Learning has come to be thought of as so important for the economic development of regions and cities that Malmberg (1997) noted a 'learning turn'. According to Hassink (2004, p. 4): 'The capacity of both individuals and organisations to engage successfully in learning processes is regarded as a crucial component of economic performance in the knowledge-based economy'.

Linking up these two perspectives on learning as both an individual (entrepreneurial) function and as a regional growth matter, learning is considered within and between organisations and individuals as a determinant for successful regions. The fact that learning takes place through organisations and individuals means that there is a strong interest in human capital, and the importance of individuals in the knowledge economy. Romer (1990, p. 97-99) goes as far as to say that 'the stock of human capital determines the rate of growth' and 'low levels of human capital may help to explain why growth is not observed in underdeveloped economies'. In addition to attracting talent from outside (cf. Florida 2006), regions must also cultivate their own human resources through learning processes. As the development of literature has been arguing the importance of learning in both contexts-regional and firm level - it is for this reason that we see theoretical value in introducing learning as a part of the EE concept.

\subsection{Entrepreneurial ecosystems and learning therein}

The EE concept has emerged as a result of combining two terms - entrepreneurial and ecosystem. The term 'entrepreneurial' refers to entrepreneurship, activities 
of creating new goods and services (Shane and Venkataraman 2000). According to early studies on $\mathrm{EE}$, the concept focuses on innovative and growthoriented entrepreneurship whilst it deliberately excludes traditional measures of entrepreneurship such as 'selfemployment' and 'small business' (Stam 2015). The second component, 'ecosystem', is defined as a union of localised cultural outlook, networks, investment capital, universities and active economic policy to create a supportive environment for innovation-based ventures (Spigel 2016). We adopt the 'entrepreneurial ecosystem' (EE) concept, as reviewed by Spigel (2017) and Malecki (2018): 'combinations of social, political, economic, and cultural elements within a region that support the development and growth of innovative start-ups and encourage nascent entrepreneurs' (Spigel 2017, p. 50).

Whilst the EE concept has much in common with other established concepts such as cluster, industrial districts and innovation systems, it also has a strong focus on the external business environment and focuses on entrepreneurs as central players in creating and sustaining the system (Stam 2015). The World Economic Forum (WEF 2013) suggests eight attributes that are critical in the development of a successful ecosystem. These pillars include accessible markets, human capital, funding and finance, support system, government and regulatory framework, education and training, major universities and cultural support. In summary, these attributes show a shift from traditional economic thinking about firms and markets to a new approach around people, networks and institutions. Emerging work in the EE domain takes a dynamic and process-based view on the entrepreneurial system, for example that by Spigel and Harrison (2018). Dynamic questions are asked such as how do we create a new ecosystem and what sustains them or what causes their decline (Stam 2014). Perspectives from evolutionary economic geography are integrated into the EE concept (Mack and Mayer 2015), examining how ecosystems evolve at the regional level (Malecki 2018).

In this study, we argue that an entrepreneurial ecosystem, when functioning well, is an interdependent set of actors that is governed in such a way that it enables high-growth entrepreneurial activities. As we illustrated above with the concept of learning, the entrepreneurial ecosystem can be conceptualised (as our interpretation of Stam 2014) as being composed of both regional attributes and individual/organisational/firm attributes. Whilst the regional attributes include physical conditions that enable or constrain human interaction in general and entrepreneurial action in particular, it also includes intangible and cultural elements. The organisational attributes include resources, finance, management and leadership, networks, intermediaries, support services and a pool of talent. The organisational attributes interact with each other and are constrained or enabled by the regional attributes. Finally, learning allows the combination of both regional and organisational characteristics to flourish and results in strong entrepreneurial activities. Learning from and between regional actors (for example, government, market) and organisational actors (for example start-ups, SMEs, industries) develops synergy and is critical for the development of EE. It is well established that entrepreneurs and the businesses they create are critical to regional and national economies of most developed countries (Jones et al. 2010). Perceived as 'tiny acorns from which large oak trees can grow' (Thorpe et al. 2009 , p. 201), there is a perspective that generating and supporting entrepreneurs and the organisations they create is something to be encouraged and revered. In response, governments especially within the developed world have sought to develop schemes and policies that encourage entrepreneurial activity (Audretsch and Link 2012); however, there have been suggestions that policy has proved ineffective to date (Arshed et al. 2014; Acs et al. 2016). A sub-stream of enterprise policy has been to encourage interaction and engagement between HEIs and entrepreneurs (Johnston et al. 2008; Zhang and Hamilton 2010), but again questions have been raised about the efficacy of driving regional economic development via the university sphere (Pugh 2017).

Within the UK, this strategy has been especially supported by government as it is seen as a way to develop higher level skills and support entrepreneurs (Lambert Review of Business-University Collaboration 2003; HMS Treasury 2006; DIUS 2009). Nevertheless, policies and business support approaches have been criticised primarily for being top down, product oriented and misaligned with what entrepreneurs and their organisations actually need (Ram and Trehan 2009). One response has been for HEIs involved in the provision of entrepreneurship education to move away from traditional ways of delivering education towards designing more innovative mechanisms through a focus on critical aspects such as entrepreneurial learning (Zhang and Hamilton 2010). However, the EE literature has not fully considered universities in terms of learning in the 
entrepreneurial ecosystem, although it states that universities are a key node in the system to encourage innovation and entrepreneurship (Miller and Acs 2017). This is the broader policy and theoretical backdrop against which we situate our paper, which now focuses in on the efforts of a particular HEI to provide support for regional development and entrepreneurship activity via a series of programmes and actions.

\section{Case introduction and research methods}

In this paper, we are presenting a case study of an institution (Lancaster University) and its wider region and demonstrate how it has attempted to respond to these core issues in the support of entrepreneurship and regional development through novel approaches to delivering support, centred around the idea of learning. This was, to a large extent, a big 'step into the unknown' (Pugh et al. 2016) and involved a high degree of trial and error and innovative working over the course of around 20 years. In this paper, we distil some of the lessons of this work, specifically how it pertains to the development and support of an entrepreneurial ecosystem in a particular region (the North West of England). In this section, we briefly provide some broader contextual background to the case, before zooming in on the particular programmes and initiatives we are analysing in this paper. Whilst we cannot fully present 20 years of work in journal paper format, in each case, we provide references to more in-depth published work on each of the programmes we discuss. We appreciate that focusing on programmes delivered by one institution means limitations to our study exist. However, considering the volume of work that has been undertaken over our 20year study period, and the novel directions pursued we see the value in presenting this single case. Comparative work has also been undertaken (Pugh et al. 2018).

\subsection{Background context}

Lancaster University was founded in 1964 and today has four faculties: Arts and Social Sciences, Health and Medicine, Science and Technology and Lancaster University Management School (LUMS), containing around twelve thousand students and two thousand staff (700 of which are academic). LUMS was the first faculty to be established and is where our case study is based.
Lancaster is a research-oriented university and in terms of both research and student experience is ranked in the top 15 in the UK's major university league tables. The university has historically been concerned with how its research can be applied for the good of society, such as the development of three knowledge business centres, including LUMS. The volume and scope of partnerships with SMEs is high for a UK higher education institution. Lancaster has delivered over 50 projects supported through EU, national and regional funds with a combined value in excess of $£ 100 \mathrm{~m}$ since 2001, working with over 5000 companies. These projects have led to the creation of over 250 new businesses and 4300 new jobs in SMEs. Projects engage in a wide range of business types, leadership development, management innovation, eco-innovation, information and communications technologies, advanced manufacturing, design and enterprise. Business engagement is a strategic priority, with a central department overseeing contracting, financial reporting and quality of business engagement. Faculties have dedicated staff who engage with businesses in various ways to ensure that the full range of research and innovation across the university is accessible. However, our focus here is on the programmes relating specifically to entrepreneurship undertaken by LUMS (Table 1).

More detailed descriptions of the university's activities and the programmes implemented already exist. Historical reviews exist of how the university's business engagement and knowledge exchange activities have evolved against broader institutional and regional cultural factors (Rose et al. 2010, 2013; Hamilton et al. 2016). Dada et al. (2016) see the university encouraging learning and business development both within their regional ecosystems, but also in other regions via a franchising model. Gordon et al. (2012) also studies one of the programmes discussed in this paper and found there to be a positive impact on SMEs and on the wider region taking part in these 'action learning' initiatives. The role of universities in the governance of regional development, drawing on the Lancaster example is also discussed (Cox and Taylor 2006; Pugh et al. 2016, 2018). Johnston et al. (2008) considered HEISME engagement from the perspective of businesses responding to the surge in interest in the economic impact of universities' third mission activities.

LUMS delivered several programmes targeted at entrepreneurs and SMEs-Entrepreneurs in Residence and Lancashire and Cumbria Regional Growth 
Table 1 Data on the North West of England

\begin{tabular}{ll}
\hline Gross disposable household income (£ million) & $211,079(2016)$ \\
Share of UK gross value added (GVA) & $9.5 \%(2016)$ \\
Total regional GVA ( $£$ billion) & $167.223(2016)$ \\
Employment rate & $74.3 \%(2018)$ \\
Manufacturing industry share of UK GVA & $13.3 \%$ \\
Population & 7259 million (2017 census) \\
Size (km sq) & 14,100 \\
Composition of regional GVA & Service industries, $50 \%$ \\
& Production industries, $28 \%$ \\
& Distribution industries, $14 \%$ \\
Proportion of working-age population with no qualifications & Construction industries, $8 \%$ \\
Total spending on R\&D ( $€)$ & $14 \%$ \\
High education institutions & 3.986 million $(2018)$ \\
Number of students & 12 universities \\
Number of patent & 250,000 \\
Number of firms & $2017: 863$ applications, 224 granted \\
& Micro (0-9 employees): 238,155 \\
& Small (10-49 employees): 24,290 \\
\hline So & Medium (50-249 employees): 4315 \\
& Total (0-249 employees): 267,765 \\
\hline
\end{tabular}

Source: Office of National Statistics 2018, 2019; 20,183; Eurostat 2017

Programmes for SMEs, innovation and creativityLondon Creative and Digital Fusion Project and LEAD 2 Innovate, and international collaborations-Berkeley Innovation Forum, KARIM, and Lancaster China Catalyst Programme. However, we chose to focus on the three programmes we had conducted research and data collection alongside, and that had also received substantial external evaluations and thus could be reasonably considered 'best practice' examples. Nevertheless, in all of these programmes, we can see the learning and social dimensions as key underpinning principles in the direction of the integrated learning model developed and used at LUMS.

Given the duration and scale of these activities, Lancaster provides an interesting perspective on an 'engaged' (Dada et al. 2016) or 'entrepreneurial' (Urbano and Guerrero 2013) university. This engagement shows a precedent of working with government at various levels and businesses, entrepreneurs and community groups in its region, and also illustrates the division's vision to become a leader in entrepreneurship research and education in partnership with business and community (Rose et al. 2010, 2013). This was achieved by undertaking and disseminating interdisciplinary research in entrepreneurship, innovation and entrepreneurial learning to inform curriculum development. At the same time, initiatives were developed which responded to identified and emerging needs within the region, through involvement in a range of partnership activities and specialist programmes targeted at supporting SME business growth. Significant funding for these activities has come from European sources; utilising universities in regional growth efforts is a key stream of activity being supported (European Commission 2011).

\subsection{Research methodology and methods}

The cases below encompass different data sources, methods and positionalities of the researchers, united by a mixed-methods case study approach using rich sources of data accessed through being positioned within the department. The access afforded to key individuals and organisations meant that an in-depth qualitative approach was possible, and we draw on multiple methods to triangulate and substantiate our findings (Denzin and Lincoln 2000). Whilst recognising the draw-back of a case study approach inasmuch as it lacks statistical validity and hypothesis testing possibilities leading to generalisability issues (Gummesson 2000), we felt that as our concern was developing understanding, rather than testing per se, that the strength of the 
case study approach outweighed its weaknesses (Chetty 1996, p. 74; Siggelkow 2007, p. 21; Eisenhardt and Graebner 2007; Yin 2012).

We used questionnaires, interviews, observations (participatory and non-participatory) and documentary evidence. Observations were carried out at programme meetings and events by the researchers, and documentary evidence was consulted is in the form of policy documents, monitoring documents and reports. Raw data were gathered, reduced and condensed and sorted into descriptive categories and themes (McKeever et al. 2015), and searched for patterns and commonalities (Jack 2005). We then sought out patterns across our data and sought explanatory factors and analytical categories (Bansal and Corley 2012).

\subsection{Analysis}

We present here three programmes whereby the university is encouraging learning for regional ecosystem development. Whilst these programmes were externally evaluated as 'successful' or best-practice cases, we also provide some inside knowledge and experience to unpack with more nuance the realities of delivering such efforts. The purpose of this analysis is to dig deeper into these programmes: how they encourage learning at both an individual, collective and wider regional level to help support the North West's entrepreneurial ecosystem. By analysing programmes that have already been implemented in such a way, we hope to draw out bestpractice lessons for others to replicate, and also highlight any problems or pitfalls to be avoided going forwards. The programmes all have, at their core, a strong principle that supporting people to learn in a reflexive manner is key to bringing about better entrepreneurial and economic development outcomes. Each draws on the socalled integrated learning model (ILM) (see Fig. 1) developed at Lancaster and embedded into the various programmes.

For the researchers and practitioners involved, it was key that programmes be driven by a theoretical understanding of how entrepreneurs, and regions, learn. The integrated learning model was developed using research on entrepreneurial learning. The model benefits from several elements that lead to transformative learning: experiential and social dimensions of learning, and reflection. This model summarises the rationale guiding the programmes we discuss, and is key in understanding

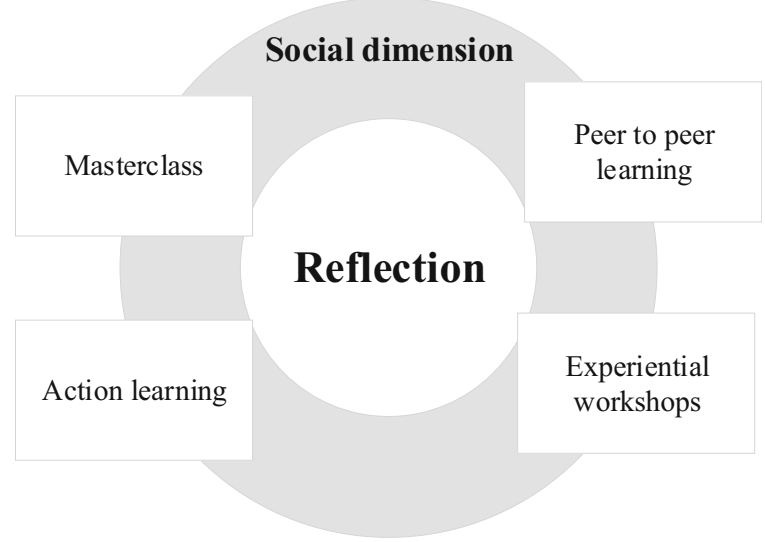

Fig. 1 Integrated learning model

the approach to developing the regional ecosystem via learning approaches.

The cases are presented chronologically and the theoretical and practical thinking around programme design and delivery evolved step-by-step as the programmes were implemented, reflected upon and evaluated. Each engagement with the local ecosystem provoked new research questions and theoretical insights, and lessons learned were fed into future programmes. The cases demonstrate increasing complexity in terms of scale and scope - the extent of collaboration required, funding to be managed, targets to be met and geographical reach. Lancaster University grew in reputation and confidence in terms of engaging SMEs in research informed programmes, but each one was in its own way a 'step into the unknown' (cf. Pugh et al. 2016) and therefore required vigilant management to meet the requirements of funders, understand the needs of the businesses and link the work to teaching and research in the university.

\section{Three cases: supporting learning in different ways}

4.1 LEAD — facilitating individual and peer learning in small businesses

The LEAD programme was funded by the regional development agency, with LUMS leading a partnership of other providers, including other universities. The programme took place from 2009 to 2011 to assist business owner-managers in the local area. The core of the programme was designed and developed by academics at LUMS specialising in leadership and 
entrepreneurial learning. This resulted in a 10-month intensive programme with emphasis on two areas: (1) improving business performance and (2) advancing the personal development of the owner-manager.

The programme comprised of several learning activities such as an overnight experiential workshop, coaching, masterclasses and action learning sets. To address actual business challenges, the programme's pedagogy focused on promoting self-confidence, critical thinking and reflection. It provided a framework for the owner-manager to innovate and grow their business through experiential and reflective learning alongside other entrepreneurs and managers. Through peerlearning activities, the participants had an opportunity to shadow fellow participants in their businesses and look at their routines and practices. As a result, the participants of the programme became part of a strong community of practice $(\mathrm{CoP})$ made up of local businesses in the region. This CoP furthered opportunities for learning from each other, and members found inspiration from their peers to grow their business. This CoP allowed the owner-managers to challenge their, and each other's, thinking and ways of working, thus learning to develop more creative and strategic approaches to their business.

The programme reached 1700 companies, employing 30,000 people with an estimated turnover of $£ 1 \mathrm{bn}$. The independent evaluation (Wren and Jones 2012) reported that LEAD produced an annual turnover growth of $13.8 \%$ and employment growth of $16.8 \%$, with $70 \%$ of participants reporting a profit increase and $65 \%$ of participants reporting a productivity increase. As a consequence of this success, the LEAD programme has been replicated in other regions by other providers nationally (Dada et al. 2016), sparked by a desire on behalf of the North West Regional Development Agency to find out if the integrated learning model and the LEAD programme could be replicated across other universities, further education colleges and private actors in the region. This roll-out proved complex and challenging for those involved.

LEAD focussed on the facilitation of individual and collective learning, thus encouraging small business owner-managers to meet their growth potential. Prior to joining the programme, most participants had already established a stable and healthy business and it was stipulated that they must express an interest to grow in order to partake. The programme sparked peer to peer learning, built up social trust at the regional level, and provided multitudinous opportunities to reflect on learning, credited with encouraging long-term success in participants' entrepreneurial endeavours (Gordon et al. 2012). LEAD is a salutary example of individual learning as a key factor in synergising and rejuvenating the EE. Reflecting on previous studies of university-SME collaboration, which have shown mixed results and a high failure rate of such programmes (Neergaard and Ulhoi 2006; Jack et al. 2008), it is notable that LEAD has proven to be successful and produced a positive multiplier effect on regional growth. We pinpoint this to the facilitation of a successful engagement process by bringing individuals within the region together in a way that was productive and meaningful for the entrepreneurs involved, and extrapolating the learning process out to the regional level through the establishment of a strong community of practice (Gordon et al. 2012; Johnston et al. 2008). The key role for the university in ecosystem development is building relationships, trust and social capital as a part of the learning process (Gordon et al. 2012). However, in implementing LEAD, the university needed to develop trust among the participants before learning took place, and build its own capacity and skills to engage and communicate with businesses. In designing LEAD the challenge was to engage with micro business, seen as a 'hard to reach' audience. The unexpected outcome was the extent of learning reported as a result of being in a trusted network. The learning through networks was then a key feature and further developed in IDEAS.

\subsection{IDEAS project—facilitating learning for scaling up technology-based firms after incubation}

The IDEAS project targeted technology-based firms located at Daresbury Science and Innovation Centre (now called Sci-Tech Daresbury), home to over 100 technology-based firms, research facilities and a science park run by the Science and Technology Facilities Council. Firms who participated in this project were mainly start-ups and engaged in an incubation process, receiving different types of support such as accommodation, funding, training and mentoring. IDEAS was run by academics from several universities in the region, including LUMS, allowing firms to benefit from the wider networks of the partner institutions. The project was delivered through a series of short, highly interactive workshop programmes, master classes, academic 
mentoring and student projects. The activities were designed to increase participants' awareness of their potential growth, obstacles after incubation and how they could learn to use their networks effectively to create sustainable change within their businesses (Jack 2005 and Jack et al. 2008). Similar to LEAD, the IDEAS project utilised learning especially in a network context to encourage and motivate entrepreneurs to move from start-up stage (team founders) to small- and mediumsized businesses. In terms of evaluations, the IDEAS project exceeded most of its original targets including businesses supported (60, original target 40), jobs created (55, target 5) and jobs safeguarded (10, target 15$)$. An external evaluation from EKOS Ltd. showed that for 'every $£ 1$ invested (in the projects), $£ 15.80$ is generated in the Northwest economy'.

IDEAS focussed on network learning to support the long-term growth of technology-based firms. This was responding to the fact that firms often suffer relatively weak performance after graduating from an incubator due their inability to become independent (Soetanto and Geenhuizen 2019), and follows the propositions of the EE approach which focuses on supporting growth rather than start-up per se. The underpinning research for this project suggested that technology-focused SMEs rarely used their available networks but were instead very $R \& D$ focused. Participants were provided with tools for visualising and reflecting on their networks and were encouraged to look at the benefits of using specific contacts in problem solving, innovation, product development and marketing. Through an interactive, hands-on network mapping exercise, delegates got a better picture of their network and how to use it to support growth. Learning was harnessed to help SMEs strategically use their networks and surrounding ecosystem to fulfil their growth potential.

With the focus on network learning, we can see this programme closely tying into the EE objectives of having an interactive and mutually supportive ecosystem for businesses. Whilst the key idea of the IDEAS project was building firms' networking capability, in this context, we assume that learning happens in the forms of problem solving, product development and knowledge transfer. The university's role in this context was to trigger the learning process and hence, this focus may overlook identifying differences in an individual's characteristics and approach. The fact that previous studies (e.g. Vissa 2012; Soetanto 2017) found that entrepreneurial networks are influenced by an entrepreneurs' style of networking, the challenge for universities is to facilitate network learning that accommodates an entrepreneurs' characteristics and their network context.

4.3 Wave 2 growth hub - facilitating regional learning through creating bespoke programmes for regional growth

With a different focus to LEAD and IDEAS, but also focussed on the issue of learning for regional growth, was the $£ 32 \mathrm{~m}$ Wave 2 Growth Hub (W2GH) Programme. This programme was designed to support the development of 15 business growth hubs in the second tier cities of England by creating jobs and economic growth outside of the largest cities. The programme was funded through the Regional Growth Fund (RGF) and was developed by LUMS in collaboration with various UK government departments, including the Cabinet Office. It was one of the first examples of a university delivering a large-scale economic development programme emanating from UK national government (Pugh et al. 2016). This, of course threw up interesting challenges for those within the university and government entering into a new type of relationship, and also signalled a new direction for the entrepreneurial department within the university (Pugh et al. 2016, 2018). The implementation of the programme involved 42 universities, 19 Chambers of Commerce and 17 Local Enterprise Partnerships (LEPs) as well as a wider network of public and private partners delivering a range of business support from face-to-face advice through to investment and grant schemes.

The role of LUMS within this was as a network enabler and facilitator of interactive learning between programme stakeholders. Due to the large scale of the programme and the geographical dispersal of the cities involved in the programme, LUMS worked to strengthen the network of the cities' stakeholders and facilitate interactive learning to allow them to exchange knowledge and continuously improve. LUMS acted as a neutral intermediary to broker issues and achieve a balance of views among stakeholders. In doing so, it gave the platform to have a collective 'voice' for policy making. The evaluation of the programme estimated that a total of 4351 jobs would be created through W2GH, far exceeding the target. The programme attracted over 
$£ 75 \mathrm{~m}$ of private sector investment to match the initial funding. It successfully attracted a total of 67,000 SMEs with $£ 2$ private sector investment for every $£ 1$ invested. As a result, the Growth Hub model has since been rolled out to all LEPs (Local Enterprise Partnerships) in England.

Similar to the other programmes, the W2GH programme had learning at the core of its delivery. However, the programme appreciated the importance of the local context and the ecosystem based view of regional economic development. If business support is to work effectively, then local context is critical and has to play a central role, and therein lies the potential to go beyond what generic business support can do. This approach allowed activities to be tailored specifically to the local context and the needs of local businesses. Moreover, the programme showed that all stakeholders in the cities should corporate and commit to learning a new approach to supporting growth in their region. The learning activities of the W2GH programme allowed each city to design their local offering based on research and their wider Strategic Economic Plan, and through local collaborations and partnerships.

Borrowing lessons from LEAD, W2GH designed a series of events based around principles of participation, engagement and reflexive learning to help the Growth Hubs grow individually and as a collective, in a similar way that was tried and tested previously with SME owner-managers. By creating formal and informal feedback mechanisms, the university was able to respond to the emerging needs of the individual Growth Hubs and the network as a collective. The context of private and public sector was different but the learning approach and interactive nature of support, and the efforts to build confidence and create a supportive network were essentially similar. Whilst managing such a large and impactful programme was an exciting and valuable activity for the university to undertake, the scale and resources required (including staffing resources and bringing in new expertise) should not be underestimated, nor should the challenges of working so closely with government agencies and 'sitting in between' different levels of government actors. ${ }^{1}$

\footnotetext{
${ }^{1}$ The pros and cons of undertaking this programme and the lessons learned are discussed in more depth in Pugh et al. 2016.
}

\section{Discussion}

5.1 Integrated learning and the importance of reflexivity for ecosystem development

We can condense our lessons from undertaking and researching these three programmes into some pertinent points when considering entrepreneurial ecosystem development. The first of these is the key role of reflection within learning. Entrepreneurs learn when they reflect on what they do and how they go about what they do in their everyday practice (Deakins and Freel 1998; Taylor and Thorpe 2004; Cope 2003). It is through learning that entrepreneurs in an EE overcome their dominant logic of being small and limited and start to expand their business. Learning and reflection are linked and can also lead to 'transformative' learning (Cope 2003, 444). From a more regional perspective, the question this throws up is (1) how we fit these concepts of learning and reflexivity into the regional entrepreneurial ecosystem? and (2) how can we design and support a reflexive EE?

We suggest the integrated learning model and embedding this into university engagement activities could hold one potential route for answering these questions. The challenge for those involved in the design of those programmes we present here was to try to find ways to facilitate 'transformative' learning within the design of the programme (see Gordon et al. 2012). What the integrated learning model has shown is that through engaging with reflecting upon experiences and behaviours, entrepreneurial learning is triggered at the individual and collective level (Gordon and Jack 2010; Cope 2001, 2003, 2005).

The second critical element for ecosystem support is that learning should be considered a social process. It is through learning from and with others that entrepreneurs in the region learned to overcome challenges and sustained business growth. A social dimension to learning has also been noted within the literature (Taylor and Thorpe 2000; Cope 2005; Pittaway and Cope 2007; Hamilton 2011), especially within models which refer to peer learning (Zhang and Hamilton 2009, 2010). Entrepreneurial learning can be facilitated through designing education programmes which bring individuals together to reflect on their own situations but also those of others and in a way which creates peer to peer learning which in turn leads to 'transformative' learning (Gordon et al. 2012; Zhang and Hamilton 2009, 2010) 
or perhaps 'coactive vicarious learning' (Myers 2018). Peer to peer learning pushes individuals to think about the experience of others and in light of their own situations (Zhang and Hamilton 2009, 2010). Peer to peer learning has also been argued to increase learning capacity (Gordon et al. 2012; Zhang and Hamilton 2010), and we can see from the experiences of the programmes we considered how this can happen beyond the individual level to a more regional ecosystemic level.

Turning to universities within the EE, our case studies illustrate how universities can indeed play a key role in strengthening and building their local ecosystem. In our case, the university has enacted its role in the region by designing programmes and events for different stakeholders in the ecosystem (from business, government, third sector) to come together, discuss, express their views and to learn from each other. The university has helped to build shared identity and a CoP around entrepreneurship in the region, through initiatives such as the three discussed here. A reflexive and interactive culture was established, where participants are encouraged to actively participate and share experiences whilst learning new skills and information from each other. Thus, the benefits of experiential learning get 'zoomed out' and amplified across a regional embedded network of entrepreneurial actors, thus forming the foundations of the regional entrepreneurial ecosystem, which coevolves via joint learning activities.

Universities are well placed to provide these learning experiences due to the presence of staff with backgrounds in teaching and the ability to facilitate learning. At the regional ecosystemic level, our experiences in Lancaster confirm previous findings in the EE literature which see universities as ecosystem hubs (Malecki 2018), fostering entrepreneurship and innovation (Miller and Acs 2017), as key nodes in the Entrepreneurial Ecosystem (Bliemel et al. 2019; Cumming et al. 2019; Liguori et al. 2019). We suggest that by taking this practical role as the learning facilitator and driver of the ecosystem, we can carve out a space in which universities can contribute positively to entrepreneurial ecosystem development and growth. Whilst it is of course challenging for those working within universities to balance these ecosystem focussed activities with their other teaching, research, and administration tasks, our experiences show real value in universities being proactively involved in their regional ecosystems. Moreover, staff gain more motivation and better recognition through the impact for their work. The design of these programmes has been theory led, based on empirical research and theory development being undertaken in the department around entrepreneurial learning, and the roles of universities in regional economic development. There was a strong desire among the academics involved in this work to ensure their research delivered real benefits to the region and positive outcomes for the local entrepreneurial community. There is also a strong desire to spread the insights gained from this work to the academic entrepreneurship community, policymakers and practitioners through the publication of journal articles, policy reports, open access blog posts and more.

\section{Conclusion}

At the start of this paper, we argued from a theoretical standing why we believe learning should be placed more explicitly within the growing entrepreneurial ecosystems concept. We saw this because of the vital importance of learning as a mechanism of both individual entrepreneurial success and also from a broader regional development perspective within the contemporary globalised knowledge economy. We also wanted to explore more of the roles of universities in the EE, which have been recognised as key nodes or hubs (Miller and Acs 2017; Malecki 2018), but have been under-explored in terms of their contribution to entrepreneurial learning at the individual and regional level, and their role in linking these two levels.

Following this theoretical foundation, we moved on to present some tangible examples of how learning can practically deliver benefits to a regional entrepreneurial ecosystem using the example of Lancaster University and the region of the North West of England, which is fairly well established in the literature as a salutary case regarding university-SME engagement (Cox and Taylor 2006; Smith et al. 2010; Gordon and Jack 2010; Rose et al. 2013; Dada et al. 2016; Hamilton et al. 2016; Schultz et al. 2016; Pugh et al. 2016, 2018). By doing so, our intention has been to link both the theoretical reasoning for nitrating learning, but also offer some practical solutions to elevate learning to the centre of EE development efforts. We wanted to extrapolate the concept of entrepreneurial learning to see how this can be amplified up to the regional level to create an ecosystem which co-evolved via learning processes. Whilst learning can indeed be included as one of the many 'institutions', using the softer sense of the term when it 
comes to entrepreneurial ecosystems, we do not see this crucial element gaining enough attention in the extant literature. Yet, we believe that researchers, knowledge exchange professionals and policymakers alike require more information about how learning can be better embedded at a regional level, and how universities can assist in this goal. We do not suggest that these three programmes we present offer the only or best way of integrating learning into the regional $\mathrm{EE}$, but they do give some examples of the range of ways in which this can be done. We also hope that by providing the integrated learning model we can share some best practice of what we have found to work in our activities, and which have helped us to have a positive impact on our local entrepreneurial ecosystem.

We also feed back into literature on the entrepreneurial university (e.g. Audretsch 2014; Lockett et al. 2012; Urbano and Guerrero 2013) by providing some examples of activities and roles universities can play to help embed learning within their regional ecosystems and strengthen the links between different players through peer to peer learning. We suggest this kind of ecosystem participation as a way for universities to go beyond narrowly defined tech transfer activities, and for academics from the social sciences and humanities to engage with local business communities by using their pedagogical skills (rather than a one way transfer of knowledge per se). The W2GH experience also showed that learning networks can be supported on a beyondregional level too. The involvement of universities in the economic development of their regions has been a growing issue over the last two decades. Governments seeking ways to boost regional economies have looked to universities, among other organisations, to support economic growth. It seems this trend will continue, and with exercises such as impact assessment feeding into the Research Excellence Framework in the UK, we, as researchers, need to become more and more conscious of how we can exert positive influence on our surrounding communities. In summary, we argue that a more thorough treatment of learning could strengthen the entrepreneurial ecosystems concept as a theoretical tool and as a policy blueprint for delivering improvements in regional economies. Through presenting three case studies of successful programmes taking what can be broadly seen as an ecosystemic view to encourage learning and create a strong culture and network of local stakeholders, we also provide practical examples of how an EE approach can be fed back into policy and practice.
Acknowledgements We would like to thank the Special Issue Editors and anonymous reviewers for their guidance and support in the writing of this paper. We would also like to say a very special thank you to all our colleagues working in the knowledge exchange team over many years at Lancaster University Management School who have helped support and deliver the programmes we discuss in this study and who also enabled our data collection. Without these colleagues, this work would not have been possible.

Funding Information Open access funding provided by Stockholm School of Economics.

Open Access This article is distributed under the terms of the Creative Commons Attribution 4.0 International License (http:// creativecommons.org/licenses/by/4.0/), which permits unrestricted use, distribution, and reproduction in any medium, provided you give appropriate credit to the original author(s) and the source, provide a link to the Creative Commons license, and indicate if changes were made.

\section{References}

Acs, Z., Åstebro, T., Audretsch, D., \& Robinson, D. T. (2016). Public policy to promote entrepreneurship: a call to arms. Small Business Economics, 47, 35-51.

Acs, Z. J., Stam, E., Audretsch, D. B., \& O’Connor, A. (2017). The lineages of the entrepreneurial ecosystem approach. Small Business Economics, 49, 1-10.

Alvedalen, J., \& Boschma, R. (2017). A critical review of entrepreneurial ecosystems research: towards a future research agenda. European Planning Studies, 25, 887-903.

Argyris, C., \& Schon, D. A. (1996). Organizational learning II: theory, method, and practice. Reading: Addison-Wesley Publishing Company.

Arshed, N., Carter, S., \& Mason, C. (2014). The ineffectiveness of entrepreneurship policy: is policy formulation to blame? Small Business Economics, 43, 639-659.

Audretsch, D. B. (2014). From the entrepreneurial university to the university for the entrepreneurial society. The Journal of Technology Transfer, 39, 313-321.

Audretsch, D. B., \& Aldridge, A. (2009). Knowledge spillovers, entrepreneurship and regional development. In R. Capello \& P. Nijkamp (Eds.), Handbook of regional growth and development theories. Cheltenham: Edward Elgar.

Audretsch, D. B., \& Belitski, M. (2017). Entrepreneurial ecosystems in cities: establishing the framework conditions. The Journal of Technology Transfer, 42(5), 1030-1051.

Audretsch, D. B., \& Link, A. N. (2012). Entrepreneurship and innovation: public policy frameworks. The Journal of Technology Transfer, 37(1), 1-17.

Autio, E., Kenney, M., Mustar, P., Siegel, D., \& Wright, M. (2014). Entrepreneurial innovation: the importance of context. Research Policy, 43, 1097-1108.

Bansal, P., \& Corley, K. (2012). Publishing in AMJ-Part 7: What's different about qualitative research? Academy of Management Journal, 55(3), 509-513.

Bliemel, M., Flores, R., De Klerk, S., \& Miles, M. (2019). Accelerators as start-up infrastructure for entrepreneurial 
clusters. Entrepreneurship and Regional Development, 31(12), 133-149.

Boucher, G., Conway, C., \& Van Der Meer, E. (2003). Tiers of engagement by universities in their Region's Development. Regional Studies, 37, 887-897.

Camagni, R. (2017). Regional competitiveness: towards a concept of territorial capital. In Seminal studies in regional and urban economics (pp. 115-131). Cham: Springer.

Chetty, S. (1996). The case study method for research in smalland medium-sized firms. International Small Business Journal, 15, 73-85.

Cope, J. (2001). The entrepreneurial experience: Towards a dynamic learning perspective of entrepreneurship. $P h D$ thesis, Lancaster University, UK

Cope, J. (2003). Entrepreneurial learning and critical reflection: discontinuous events as triggers for 'higher-level learning. Management Learning, 34(4), 429-450.

Cope, J. (2005). Towards a dynamic learning perspective of entrepreneurship. Entrepreneurship: Theory and Practice, 29(4), 373-397.

Corbett, A. C. (2005). Experiential learning within the process of opportunity identification and exploitation. Entrepreneurship Theory and Practice, 29(4), 473-491.

Cox, S., \& Taylor, J. (2006). The impact of a business school on regional economic development: a case study. Local Economy, 21(2), 117-135.

Cumming, D., Werth, J. C., \& Zhang, Y. (2019). Governance in entrepreneurial ecosystems: venture capitalists vs. technology parks. Small Business Economics, 52(2), 455-484.

Dada, O., Jack, S., \& George, M. (2016). University-business engagement franchising and geographic distance: a case study of a business leadership programme. Regional Studies, 50, 1217-1231.

Deakins, D., \& Freel, M. (1998). Entrepreneurial learning and the growth process in SMEs. The Learning Organization, 5(3), 144-155.

Denzin, N., \& Lincoln, Y. (2000). Handbook of qualitative research (2nd ed.). London: Sage.

Department for Innovation, Universities and Skills (DIUS) (2009) Departmental Report 2009

Dimov, D. (2007). Beyond the single-person, single-insight attribution in understanding entrepreneurial opportunities. Entrepreneurship Theory and Practice, 31(5), 713-731.

Eisenhardt, K. M., \& Graebner, M. E. (2007). Theory building from cases: opportunities and challenges. Academy of Management Journal, 50, 25-32.

European commission. (2011). Connecting Universities to Regional Growth: A Practical Guide.

Fischer, M. M., \& Nijkamp, P. (1988). The role of small firms for regional revitalization. The Annals of Regional Science, 22(1), 28-42.

Florida, R. (2006). The flight of the creative class: the new global competition for talent. Liberal Education, 92, 22-29.

Gordon, I., \& Jack, SL. (2010). HEI engagement with SMEs: Developing social capital. International Journal of Entrepreneurial Behavior \& Research, 16(6): 517-539.

Gordon, I., Hamilton, E., \& Jack, S. (2012). A study of a university-led entrepreneurship education programme for small business owner/managers. Entrepreneurship \& Regional Development, 24, 767-805.
Gummesson, E. (2000). Qualitative methods in management research. Thousand Oaks: Sage.

Hamilton, E. (2011). Entrepreneurial learning in family business: a situated learning perspective. Journal of Small Business and Enterprise Development, 18(1), 8-26.

Hamilton, E., Fogg, H.E., Jack, S.L. and Schultz, F. (2016) Entrepreneurship at Lancaster University Management School - Department for Entrepreneurship, Strategy and Innovation, in M. Morris (Ed), the Annals of Entrepreneurship Education and Pedagogy. Cheltenham: Edward Elgar p. 334-342.

Harrison, R. T., \& Leitch, C. M. (2005). Entrepreneurial learning: researching the interface between learning and the entrepreneurial context. Entrepreneurship Theory and Practice, 29(4), 351-371.

Hassink, R. (2004). The learning region: A policy concept to unlock regional economies from path dependency. In Bericht für die Konferenz: Regionalization of Innovation Policy-Options and Experiences.

HM Treasury. (2006). Science and innovation investment framework 2004-2014: Next steps. London: HMSO Retrieved from http://www.interdisciplines.org/interdisciplinarity.

Huggins, R., Jones, M., \& Upton, S. (2008). Universities as drivers of knowledge-based regional development: a triple helix analysis of Wales. International Journal of Innovation and Regional Development, 1, $24-47$.

Jack, S. L. (2005). The role, use and activation of strong and weak network ties: a qualitative analysis. Journal of management studies, 42(6), 1233-1259.

Jack, S., Dodd, S. D., \& Anderson, A. R. (2008). Change and the development of entrepreneurial networks over time: a processual perspective. Entrepreneurship and Regional Development, 20(2), 125-159.

Johansson, B., Karlsson, C., \& Stough, R. (2011). Theories of endogenous regional growth-lessons for regional policies. In Theories of endogenous regional growth (pp. 406-414). Berlin, Heidelberg: Springer.

Johnston, L., Hamilton, E., \& Zhang, J. (2008). Learning through engaging with higher education institutions: a small business perspective. International Small Business Journal, 26(6), 651-660.

Jones, O., Macpherson, A., \& Thorpe, R. (2010). Learning in owner-managed small firms: mediating artefacts and strategic space. Entrepreneurship and Regional Development, 22(78), 649-673.

Kolb, D. (1984). Experiential learning as the science of learning and development. Englewood Cliffs: Prentice Hall.

Lambert, R. (2003). Lambert review of business-university collaboration.

Liguori, E., Bendickson, J., Solomon, S., \& McDowell, W. (2019). Development of a multi-dimensional measure for assessing entrepreneurial ecosystems. Entrepreneurship and Regional Development, 31(1-2), 7-21.

Lockett, N., Rose, M., Robinson, S., \& Jack, S. (2012). Opportunities, contradictions and attitudes: the paradox of university-business engagement since 1960. Business History, 55(2), 259-279.

Lumpkin, G. T., \& Lichtenstein, B. B. (2005). The role of organizational learning in the opportunity-recognition process. Entrepreneurship Theory and Practice, (4), 451-472. 
Lundvall, B.-Å. (1992). National innovation systems: towards a theory of innovation and interactive learning. London: Pinter.

Mack, E., \& Mayer, H. (2015). The evolutionary dynamics of entrepreneurial ecosystems. Urban Studies, 53, 2118-2133.

Malecki, E. J. (2018). Entrepreneurship and entrepreneurial ecosystems. Geography Compass, 12, e12359.

Malmberg, A. (1997). Industrial geography: location and learning. Progress in Human Geography, 21, 573-582.

McKeever, E., Jack, S., \& Anderson, A. (2015). Embedded entrepreneurship in the creative re-construction of place. Journal of Business Venturing, 30, 50-65.

Mezirow, J. (1991). Transformative dimensions of adult learning. San Francisco: Jossey-Bass.

Miller, D. J., \& Acs, Z. J. (2017). The campus as entrepreneurial ecosystem: the University of Chicago. Small Business Economics, 49, 75-95.

Morgan, K. (2004). The exaggerated death of geography: learning, proximity and territorial innovation systems. Journal of Economic Geography, 4, 3-21.

Morgan, K. (2007). The learning region: institutions, innovation and regional renewal. Regional Studies, 41, 147-S159.

Morris, M. H., Kuratko, D. F., Schindehutte, M., \& Spivack, A. J. (2012). Framing the entrepreneurial experience. Entrepreneurship Theory and Practice, 36(1), 11-40.

Myers, C. (2018). Coactive vicarious learning: toward a relational theory of vicarious learning in organizations. Academy of Management Review, 43(4), 610-634.

Neergaard, H and Ulhoi, J. (2006). Government agency and trust in the formation and transformation of interorganizational entrepreneurial networks. Entrepreneurship: Theory and Practice, 30, 519-39.

Office for National Statistics. (2018). Statistical Bulletin: UK business, activity, size and location. Retrieved from .https://www.ons.gov.uk/businessindustryandtrade/ business/activitysizeandlocation/bulletins/ ukbusinessactivitysizeandlocation/2018

Office for National Statistics. (2019). Statistical Bulletin: GDP. Retrieved from https://www.ons.gov. uk/economy/grossdomesticproductgdp

Pitelis, C. (2012). Clusters, entrepreneurial ecosystem co-creation, and appropriability: a conceptual framework. Industrial and Corporate Change, 21, 1359-1388.

Pittaway, L., \& Cope, J. (2007). Simulating entrepreneurial learning: integrating experiential and collaborative approaches to learning. Management learning, 38(2), 211-233.

Pugh, R. (2017). Universities and economic development in lagging regions: 'triple helix' policy in Wales. Regional Studies, $51,982-993$.

Pugh, R., Hamilton, E., Jack, S., \& Gibbons, A. (2016). A step into the unknown: universities and the governance of regional economic development. European Planning Studies, 24, 357-1373.

Pugh, R., Lamine, W., Jack, S., \& Hamilton, E. (2018). The entrepreneurial university and the region: what role for entrepreneurship departments? European Planning Studies, 26(9), 1-21.

Ram, M., \& Trehan, K. (2009). Critical by design: enacting critical action learning in a small business context. Action Learning: Research and Practice, 6(3), 305-318.
Romer, P. M. (1990). Endogenous technological change. Journal of Political Economy, 98, 71-S102.

Rose, M., Smith, S., \& Hamilton, E. (2010). The story of a university knowledge exchange actor-network told through the sociology of translation: a case study. International Journal of Entrepreneurship Behaviour and Research, 16, 502-516.

Rose, M., Decter, M., Robinson, S., Jack, S., \& Lockett, N. (2013). Opportunities, contradictions and attitudes: the evolution of university-business engagement since 1960. Business History, 55, 259-279.

Rutten, R., \& Boekema, F. (Eds.). (2007). The learning region: foundations, state of the art, future. Cheltenham: Edward Elgar.

Schultz, F., Fogg, H., Hamilton, E. and Jack, S.L. (2016) Case study: Department for Entrepreneurship, Strategy and Innovation - Lancaster University (UK), in G. Maas and P. Jones Entrepreneurship centres: global perspectives on their contributions to higher education institutions. Palgrave Macmillan

Shane, S., \& Venkataraman, S. (2000). The promise of entrepreneurship as a field of research. Academy of Management Review, 25, 217-226.

Siggelkow, N. (2007). Persuasion with case studies. Academy of Management Journal, 50, 20-24.

Smith, S, Rose, M, Hamilton, E. (2010). The story of a university knowledge exchange actor-network told through the sociology of translation: A case study. International Journal of Entrepreneurial Behavior \& Research, 16(6): 502-516.

Soetanto, D. (2017). Networks and entrepreneurial learning: coping with difficulties. International Journal of Entrepreneurial Behavior \& Research, 23(3), 547-565.

Soetanto, D. and van Geenhuizen, M. (2019). Life after incubation: The impact of entrepreneurial universities on the longterm performance of their spinoffs. Technological Forecasting \& Social Change, 141, 263-276.

Spigel, B. (2016). Developing and governing entrepreneurial ecosystems: the structure of entrepreneurial support programs in Edinburgh, Scotland. International Journal of Innovation and Regional Development, 7(2), 141-160.

Spigel, B. (2017). The relational organization of entrepreneurial ecosystems. Entrepreneurship Theory and Practice, 41, 4972.

Spigel, B., \& Harrison, R. (2018). Toward a process theory of entrepreneurial ecosystems. Strategic Entrepreneurship Journal, 12(1), 151-168.

Stam, E. (2014). The Dutch entrepreneurial ecosystem. Available at SSRN: $\mathrm{https}: / / \mathrm{ssrn} . \mathrm{com} / \mathrm{abstract}=2473475$

Stam, E. (2015). Entrepreneurial ecosystems and regional policy: a sympathetic critique. European Planning Studies, 23(9), 1759-1769.

Stam, E., Bosma, N., Van Witteloostuijn, A., De Jong, J., Bogaert, S., Edwards, N., \& Jaspers, F., (2012). Ambitious entrepreneurship. A review of the academic literature and new directions for public policy, report for the Advisory Council for Science and Technology Policy (AWT) and the Flemish Council for Science and Innovation (VRWI).

Statistical Office of the European Communities (2017). Eurostat regional yearbook. Luxembourg, Eurostat. 
Statistical Office of the European Communities (2017). Eurostat: Regional statistics. Retrieved from https://ec.europa. eu/eurostat/web/regions/data/database

Storper, M. (2010). Agglomeration, trade, and spatial development: bringing dynamics back. International Journal of Regional Science, 50, 313-342.

Taylor, D.W., and R. Thorpe. (2000). The owner-manager, No isolated monad: Learning as a process of co-participation. Proceedings of the 23rd ISBA National Small Firms Policy and Research Conference, 1185-99.

Taylor, D. W., \& Thorpe, R. (2004). Entrepreneurial learning: a process of co-participation. Journal of Small Business and Enterprise Development, 11(2), 203-211.

Thorpe, R., Cope, J., Ram, M., \& Pedler, M. (2009). Leadership development in small-and medium-sized enterprises: the case for action learning. Action Learning: Research and Practice, 6(3), 201-208.

Urbano, D., \& Guerrero, M. (2013). Entrepreneurial universities. Economic Development Quarterly, 27, 40-55.

Vissa, B. (2012). Agency in action: Entrepreneurs' networking style and initiation of economic exchange. Organization Science, 23(2), 492-510.
World Economic Forum [WEF]. (2013). Entrepreneurial ecosystems around the globe and company growth dynamics: industry agenda. Geneva: World Economic Forum.

Wren, C., and Jones, J. (2006). Ex-post evaluation of the LEAD Programme. Unpublished report. http://www.lums.lancs.ac. uk/leadeval. Accessed August 242010

Yin, R. K. (2012). Applications of case study research (3rd ed.). Thousand Oaks: SAGE.

Zahra, S. A., Wright, M., \& Abdelgawad, S. G. (2014). Contextualization and the advancement of entrepreneurship research. International Small Business Journal, 32, 479-500.

Zhang, J and Hamilton, E. (2009). Engaging HEIs in business and the community: A learning perspective. Education and Training, 51(8/9), 607-23.

Zhang, J., \& Hamilton, E. (2010). Entrepreneurship education for owner-managers: the process of trust building for an effective learning community. Journal of Small Business \& Entrepreneurship, 23(2), 249-270.

Publisher's note Springer Nature remains neutral with regard to jurisdictional claims in published maps and institutional affiliations. 